ease of the alimentary tract. The stomach, as well as the intestines, requires absence from occupation, rest, and it should be in proportion to the severity and duration of the symptoms they present." BIBLIOGRAPHX.

Articles "Repos" and "Loi d'Intermittence," Dictionnaire de Médicine (Littre's), Paris, 1886; article "Repos" in Dictionnaire des Sciences Gould's lictionaries.

Belknap, L. J.: The rest cure, the cases selected; method of treatment, Mich. Med. Societs, Detroit, 1892, xvi, p. 161.

Battey, R.: Rest, the great panacea for human ills, Trans. Med. Associa tion, Georgia, Atlanta, 1877.

Blatchford, T. W.: Report on rest and the abolition of pain in the treatment of disease, Tr. Med. Society, N. Y., Albany, 1856.

a.: Del reposo qual mezzo terapeutico, Gaz. Féd. Ital. Lamb. Hilano, 18 the rina 1, p.

bilite dans le traitement des affections chirurgicales, Paris, 1844

Her Theile und Stabilitiits-neurosen, Arch. (18)

Journal, 1891. ii, p. 23\%. Lancet, 1891, ii, p. 222 .

Dippe, E.: Ruhe als Wundheilmittell, Schmiedeberg, 1876

Dyson, W.: Some difficulties met with in the employment of rest as a therapeutic agent in medical cases, Med. Press and Circ., London, 1884, n. s. xxxvii, p. 43 .

Finney, J. M.: Rest, a therapeutic agent in the treatment of diseases, more particularly of diseases of the circulatory system, Dublin, Jour-

Hilton, J.: On rest and pain, Lancet, London, 1861, ii ; 1862, $\mathrm{i}$ and ii; àso New York, 187

Hammond, W. A.: How to rest, N. Am. Review, N. Y., 1891, cliii, p. 215. Jackson, A.: Changed aspects of unchanged truths; the use and abuse of rest, Med. Press and Circular, 1885, n. s. xxxix, p. 80

Jacobi Mary Putnam: Rest for women.

nes, R.: On the so-called a buse of rest, Liverpool Med. Chirur. Journal, 1886 , vi, p. 18.

sur le movement et le repos, Memoire de l'Acad. Roy. de Chirurg., 1779

disease, 1879 , i, p. 474 . Maryland Med. Jour., Baltimore, 1891-92, to which

Page, F. W.: Permanency of the rest treatment, Boston Med and Surg. Journal, 188\%, cvii, p. $77-81$.

Pope, C.: A plea for the more systematic care and attention of chronic function disease by the rest treatment, Charlotte (N. C.) Med. Journal, 1896 , ix, p. $444-446$.

Reyne: Memoir sur le movement et le repos, Mem. de l'Acad., Roy. de Chir., 1780.

Rambaud, $C_{1}:$ Du repos envisage comme moyen therapeutic, Paris, 1871. Roberts, F. T. On rest and position in the treatment of medical diseases, Liverpool Med. and Surg. Reporter, 1868, ii, p. 39.

Sinkler, W.: Discases and conditions to which the rest treatment is adapted, Jour . Ner. and Mental Diseases, N. Y., 1892, xix, p. 321-338.

Tajeris

Therapeutic Gaz. DISCUSSION.

Dr. H. M. McConnell of Penngylvania-I do not think there is any class of cases that require rest so much as diseases of the stomach. Rest of this organ means physiologic rest. The only way to obtain this rest is to abstain from food entirely and this can only be done to a very limited extent, when it can be carried out at all. When the Doctor gave the history of his cases he did not say what they were being treated for; in some cases it is injudicious to give nitrogenous food. Some symptoms are due to auto-intoxication, and you must improve digestion in treating these cases. Take ordinary typhoid fever, a patient that takes three or four pints of milk a day is not giving the organs physiologic rest. When you take into consideration imperfect digestion, most cases of neurasthenia are cases of auto-intoxication. Physiologic rest is very important.

Dr. Tyson of Philadelphia-In speaking upon the rest treatment of gastro-intestinal troubles the Doctor has spoken of the one thing that will do more or less good in every case of these troubles; the application of therapeutic measures in these gastro-intestinal troubles is more or less haphazard. Those who look into the subject do not receive much assistance so far as therapeutic measures go. I hope the time will $\operatorname{come}$ when accurate methods will produce more satisfactory results. In comparison to the rest treatment of the stomach, the Weir Mitchell method is rather analogical. In my experience food is not such a necessary factor in the treatment of these conditions as many would imagine. A patient may go one, two or three days without the ingestion of food, if he is in a position not to demand any force; food is a force-producing agent largely.

Dr. H. A. West of Galveston, Texas-The scope of Dr. Spivak's paper is very comprehensive, because the gastro. intestinal canal undergoes serious involvement in nearly all infectious diseases, such as rheumatism, scarlet fever, measles and diseases of that class, in which the processes of digestion are seriously involved. Rest treatment is of supreme value, not only rest so far as can be accomplished by rest in bed, but by other means. And especially as regards acute rheumatism, the prognosis in this disease as regards the subse- uent cardiac complications can be made less or even averted by such a plan of rest in bed. The whole subject is so com prehensive that one can not discuss it in the five minutes allowed him. One point would require modification - as to the necessity of rest in all cases of tuberculnsis. If the rest in these cases is limited to the organs of digestion and to the proper regulation of the diet, then I agree with the Doctor but the large proportion of cases is benefited by exercise in the open air.

Dr. SpIvak of Colorado-I have little to say in addition to what I have already said. I am thankful to Dr. Tyson for taking. up the defense. I read the paper not so much to relate to you the nine cases as to urge upon you the necessity of rest in these cases. I wanted to arouse interest in the profession to one of the best methods that can be used and one which nature employs to cure disease. 1 have been interested in this subject many months. I am sorry that the facil. ities of the library here does not permit of more extended research on this subject; there are only fifteen or eighteen papers or monographs in the whole literature on the subject of rest. I have not found one school that treats of the subject of rest in gastro.intestinal disorders. I have seen good results in many cases and in none have I seen any harm result. In regard to tuberculosis, I did not mean to say that all cases should be treated by rest in bed; I said that those cases that were suffering from fever should go to bed. My opinion is based upon a good many cases observed. They feel a great deal better in bed than they do after a walk. Every patient who has a fever, when he exerts takes something away from his strength. Furthermore, I stated that patients who suffered from diarrhea or vomiting should also go to bed. I limit these cases where rest in bed is indicated in tuberculosis where there is temperature, diarrhea and vomiting.

\section{DILATATION OF THE STOMACH, WITH REPORTS OF CASES TREATED BY DIET, MASSAGE AND INTRA. GASTRIC ELECTRICITY.}

Presented to the section on Practice of Medicine at the Forty-ninth Annual Meeting of the American Medical Association, held at Denver, Colo., June 7-10, 1898. BY BOARDMAN REED, M.D. PHILADELPHIA, PA.

There has been a tendency of late among writers to regard enlargements of the stomach as of little or no consequence, unless very excessive and complicated by such a degree of muscular weakness as to render the organ incapable of emptying itself at any time during the twenty-four hours. Some recent authors do not give any place to dilatation of the stomach as a distinct or separate entity, but describe it incidentally under the heads of motor insufficiency and obstruction at or near the the pylorus, on the ground that it is a mere sequela or consequence of one of these. But, notwithstanding the high authority which exists for a contrary view, the writer insists that there is a normal size for stomachs as much as for hearts, and that any notable enlargement of either, plus decided insufficiency, constitutes dilatation. It is granted that it is not in either case a primary disease, and also on account of the enormously disturb. ing influence of unhygienic diet and dress, stomachs do differ very widely in size within so-called normal limits; but even the cases called megalo-gastria by Ewald,' in which in consequence of excessive eating or drinking the stomach is often found twice the usual size without indigestion, are no more normal than are hypertrophied hearts in which the circulation is well maintained. The enlarged stomachs which have not yet dilated are, in fact, very frequently a cause of other pathologic conditions and of symptoms both direct and indirect, especially by displacement of the uterus.

But to follow up this line of discussion would lead too far afield. The object of this paper is to show 
the amenability to treatment of a certain class of in these the gastric mucosa was manifestly less sencases in which the stomach as a result usually of sitive and could better bear the powerful direct stimhygienic errors, often dating from faulty feeding in ulation required to contract the muscular walls. In infancy, has become decidedly enlarged and weakened, one of these two cases the increase was temporary and cases, which while much less serious than those the proportion of $\mathrm{HCl}$ declined again during the furdependent upon pyloric obstruction, have been con. ther treatment; in the other one a small family batsidered rather refractory to our usual therapeutic tery was used at the patient's house, not the stronger measures, if not quite incurable. The preponderance apparatus with high tension coil employed in my other of such cases as well as of gastroptosis in women, cases. even in young unmarried women in whom child-bearing can not be invoked as a cause, points to the probability that their mode of dress is a factor in the etiology.

Ewald ${ }^{2}$ says: "I understand dilatation of the stom. ach or gastrectasia to be that condition of the viscus which is accompanied by the clinical symptom of disturbed gastric function due to the enlargement of the organ." This definition will answer perfectly well for the purposes of the present discussion.

I have not tried the experiment of giving small doses of intragastric electricity to increase the action of the glands, since abdominal massage and hydrochloric acid administered as a remedy are sufficiently effective for this purpose, and much pleasanter, but I do not doubt that faradism applied in this way would prove a safe glandular stimulant.

Fifteen patients in all have received intragastric electricity from me. Twelve of these had enlarged stomachs with more or less muscular insufficiency.

Mathieu's division of atonic dilatation into "tem. One of those residing at a distance has received only porary" and "permanent" can not be accepted, since two electric treatments at long intervals and no result experience teaches that by our latest resources, includ- in this case could yet be expected. In all the remaining intragastric electricity and abdominal massage, ing eleven there has been a decided reduction in the with the help of diet, exercise, and in bad cases, lav- size of the stomach, with an increase in the motility. age, all the atonic forms of dilatation can at least be In one of these, a case of hypopepsia with aggravated greatly improved. The mildest cases and some of the worse ones, will often yield to diet and exercise alone. The more severe ones, including even those of long standing and those complicated by gastritis, will usually improve greatly upon a careful, non-fermentable diet, ${ }^{+}$lavage, special exercises for strengthening the abdominal muscles and either massage of the abdomen or intragastric electricity, the chcice being dependent upon the activity of the secretion of the gastric glands. Massage suits best when there is a deficiency of the gastric juice and is apt to aggravate when there is hyperchlorhydria, as pointed out in a previous paper by the writer. ${ }^{.}$This aggravation is especially to be apprehended from a deep, thorough kneading.

Intragastric electricity in the form of a strong faradic current is very efficient in strengthening the weakened gastric muscle and in contracting the dilated organ. As mentioned by me in a former contribution, in which is described a new intragastric electrode ${ }^{6}$ it will, in suitable cases, often cause a retraction of the lower border of the stomach to the extent of a full inch at one sitting, demonstrating beyond cavil that it does stimulate the gastric muscle directly, and in a most positive manner. Of this marked retraction each time only a small part persists, but in the pure atonic cases it has been usual to see a permanent gain of from one to two inches as a result of twelve to twenty treatments given from five to eight minutes at a time on alternate days. Some cases treated every day responded even more rapidly, but my experience points to the need of caution in this respect, as in some of my cases there was at the same time rapid lessening of $\mathrm{HCl}$, and, later, after this had gone below the normal, there resulted nausea, loss of appetite, etc., from the further electric treatments, showing over-stimulation and depression of the glandular function.

On the other hand, in two cases of chronic gastritis with deficient secretion and enormons dilatation, similar treatment along with lavage, massage and the administration of $\mathrm{HCl}$ internally were followed by an increase in the amount of the secretion, at the same time that the stomach contracted. But of fluid with each meal, including soup, but they have 
been allowed, and, except in the worst gastrectasis, urged to drink water often between meals, though never more than one glassful at a time.

The great majority of these enlarged and weakened stomachs by the time they have come under methodical treatment have developed some degree of intlam. mation of the mucous membrane. One of the familiar types of chronic gastritis has been set up. More often than othermise, as seen by me, the gastritis has been accompanied by either a normal or excessive secretion of $\mathrm{HCl}$, and it is worthy of note that catarrhal inflammation with much mucus, rapid multiplication of bacteria, especially yeast fungi, and excessive fermentation, proves more difficult to overcome than the other morbid conditions. In other words, I have found it easier to strengthen and contract an atonic, dilated stomach and to relieve an accompanying hyperchlorhydria, when present, than to cure the coexisting gastric catarrh. One reason for this is that patients rarely are willing to continue treatment after they have ceased to suffer much inconvenience, and when both the motor function and the secretion of the gastric juice have been brought to the normal, the remaining catarrh usually produces few symptoms, though a low grade inflammatory process lingers. The patients considering themselves virtually well, abandon treatment and then, even if they do not drift back into their former faulty habits, as they are so prone to do, there is a tendency especially in those past middle age or at any age with poor reparative powers, for the remaining foci of disease to persist and to increase again upon the slightest provocation.

Case 1.-Lady, married, aged 45, has been under my care for the past year on account of chronic gastric and duodenal catarrh, with greatly deficient secretion of $\mathrm{HCl}$ and marked dilatation of the stomach, complicated by slight gastroptosis, and also by violent attacks of gastric pain. This case is fully reported in another paper to be read at the present meeting of the Association before the Section on Materia Medica and Therapeutics, but a brief account of it will be of interest in this connection. The patient residing at a distance from the city, in a town where there was no masseuse, and being unable to remain under my immediate care, the treatment was necessarily limited to diet and internal medicines mainly. She was required to eat moderate meals only, never overloading the stomach, and to avoid especially sugar, fried things, nuts, shell fish, except raw oysters, and hot or fresh bread. Her medica tion comprised $\mathrm{HCl}$ and pepsin on account of the marked defi ciency of the gastric juice, and during part of the time small doses of nitrate of silver in pill form. She received no mas sage or intragastric electricity. By the end of a year the lower border of her stomach had retracted fully two inches at the same time that the proportion of $\mathrm{HCl}$ and of the ferments had returned to about the normal. Her painful attacks had also ceased to recur.

Case 2.-Unmarried lady, teacher, came under treatment in the autumn of 1897 , complaining of chronic indigestion with almost daily vomiting and headaches. This case was referred to me by Dr. Samuel Bolton of Frankford, and is also reported in the paper above mentioned, to be presented before another Section at this meeting of the Association. The salient facts will be very briefly summarized here. Upon beginning treatment there was moderate dilatation as well as chronic gastric catarrh and hypopepsia. The lower border of the stomach was a half inch below the level of the umbilicus and the motility was poor. When she last consulted me, A pril 9, 1898, her stomach had retracted to within normal limits and the percentage of $\mathrm{HCl}$ and of the ferments was fully up to the normal. There had been no vomiting or headache for three months. The treatment had been diet, much the same as in Case 1, and the administration of $\mathrm{HCl}$ and pepsin mainly. She had also been taught to wash out her own stomach and had done this every day at first, and latterly two or three times a week.

Case 3.-A gentleman, aged 53, has been under observation off and on for the past four years. When he first consulted me he had some acid gastric catarrh, with occasional transient attacks of catarrh of the small intestine, and constipation. His stomach walls were very atonic and the organ extended to the level of the navel, with weak circulation and neurasthenia. Diet and medication at first accomplished very little except to lessen the catarrh and resulting fermentation. During the past winter systematic autolavage was practiced by him for several weeks on alternate mornings, and by means of this, together with a judicious administration of a pill of extract of belladonna and extract of yerba santa (the latter being an excellent sedative apparently to all the branches of the pneumogastric) varied oceasionally by giving full doses of alkalies, the catarrhal process was greatly benefited and the $\mathrm{HCl}$ secretion reduced to the normal at the same time that the stomach began to lessen in size. Massage, both abdominal and gen eral, was then added to the treatment and continued almost daily for one month. Later the patient learned to masece his own abdomen, and has since continued it. His stomach is now (May 15) within normal limits, the lower border being fully two inches above the navel and no splash is obtainable, even after drinking a glass of water. Bowels moved now easily with gr. one-tenth of aloin. Exercise with the pulleys has been practiced though not very regularly.

Case 4..-Unmarried lady, aged 25, came under my care first in A tlantic City in the summer of 1897. History of som $\theta$ obscure stomach trouble for six years and for a year or more past patient has had dull pain and nausea nearly every day, coming on soon after eating with frequent attacks of severe gastralgia, and occasionally marked vertigo. She was plump, well nourished and of good color, in spite of extensive atonic dilatation and very aggravated chronic gastric catarrh. The upper boundary of her stomach was in the normal place while the lower border was three to four inches below the level of the umbilicus as shown by percussion, the splash and the gastrodiaphane. The stomach was never found empty except before breakfast and not always then. There were the usual signs of stagnation and excessive fermentation of food. Microscopic examination showed the stomach mucus to be swarming with yeast fungi. There were occasional attacks of acute intestinal catarrh, which yielded with difficulty, and always violent pelvic pain at the menstrual period. Large and repeated doses of anodynes had been required for the dyemenorrhea and of ten at other times for the gastralgia. The stomach was washed out and a strict diet was enforced. Intragastric electricity in the form of a mild galvanic current-M.A. 5 to 10 , the positive pole inside and negative pole in the form of a large flat electrode placed over the stomach-effected more relief to the gastrio pain than any other ageucy. But the relief was temporary. The stagnation and excessive fermentation in a very largely dilated stomach were clearly the chief causes. Finally lavage was regularly employed and the high tension faradic current in as strong dose as could comfortably be borne, was used on an average every second day fcr at first ten minutes at a time, but later on, this dose having seemed excessive, the time of each sitting was limited to five minutes. There had never been any free $\mathrm{HCl}$ in the stomach since the patient had been under observation. though the T.A. an hour after a test breakfast was usually 50 to 60 , representing largely fermentation products. After the intragastric faradism had been continued for several weeks a trace of free $\mathrm{HCl}$ once appeared in the gastric contents, but none has ever been found since.

Under this energetic treatment, continued more or less regularly for three months, the stomach walls gradually contracted and now the lower border is just above the level of the umbillicus. There was, however, during the latter part of the time that the intragastric faradism was being used regularly, a loss of digestive power and a return of nausea, vomiting and dizziness, symptoms which had previously troubled her much, but had been greatly relieved by lavage and restricted diet. During the last two months the latter measures have been relied on chiefly, with some help from external electric applica. tions, and the patient, while retaining the gain in the size and motility of the stomach which the intragastric faradism helped to effect, is continuing to make satisfactory progress in other ways. There is no more nausea, less dizziness, and greatly less gastric pain, though there is still some mucus secreted daily in her stomach. A highly nervous temperament has complicated the case, and lack of means to obtain massage treatment has been an unfortunate embarrassment. A retrac. tion of fully three inches in the size of such a seriously dilated stomach is, however, a striking evidence to the power of intragastric faradism in such cases.

Case 5.-Widow; aged 64 : resident in a neighboring city; came under treatment Oct. 13, 1897, with complaint of cardiac palpitation and flatulent dyspepsia, dating back a year or more. She had been troubled much longer with constipation and occasional headache. A strong, active, energetic and well nourished woman, weighing 150 pounds, she complained of a painful dragging in the abdomen in walking, especially in going 
up-stairs. Examination revealed an exceptionally sound, strong heart of normal size, with normal lunge and liver, and kidneys not displaced, but her stomach was enlarged from the usual level above to three and a half inches below the umbilicus. The usual tests showed only a little motor deficiency, and a small, mixed meal would leave the stomach in four to five hours, yet there was an abnormally loud and large splash after drinking a glass of water, and this together with the sen sation of weight and dragging after meals, pointed to the fact that the enormously enlarged stomach was not in a proper tonic condition as to its musculature, or to use the cardiac phraseology, that there was hypertrophy, with some dilata tion. The analysis of the stomach contents revealed marked hyperchlorhydria and a large amount of mucus with other signs of chronic acid gastric catarrh.

The treatment at first consisted mainly of remedies to re duce the hyperchlorhydria; and simple, plain diet, as little fer mentable as poseible, with lavage when she could come to the office, which was only at long intervals. Later she came to the city and began a more systematic treatment. Intragastric faradism was now given on alternate days - sometimes every day-with the result of rapidly contracting the stomach. The action on the glandular function was less favorable than in any of the other cases. When the sittings were daily for five minutes during one week, there was a decided increase in the percentage of free $\mathrm{HCl}$, the only instance in which this resulted, in my experience, in a case of hyperchlorhydria. There was also nausea after the latter treatments. Massage was thereupon ordered instead. This was given vigorously over the body generally, but very lightly over the abdomen -little more than effieurage. Lavage was also given every morning for a while, and later every other morning before breakfast. The hyperchlorhydria was not reduced so readily as usual, requiring a pill of belladonna and yerba santa to be continued for some time before coming under control. The lower border of the stomach now, May 15, is one inch above the level of the umbilicus, when the patient stands after drinking a glass of water. This is a reduction in size of over four inches. The gastritis is also greatly improved. The patient is still under treatment.

Case 6.-Widow; aged 38 ; has been for years a eufferer from indigestion and neurasthenia, dependent upon acid gas. tric catarrh, dilatation of the stomach and a right floating kid. ney. There has been a remarkably relaxed condition of her tissues in all parts of the body, and yet singularly, she is almost the only lady patient seen by me with a marked dilatation of the stomach (or with gastroptosis) who has not had at the same time a displaced uterus. She had been under the professional care of various specialists on account of these ailments. During the past year and a half she has consulted me with more or less regularity. In the winter and spring of 1896-7, she made some little favorable progress as a result of diet, physical culture, massage, occasional lavage, and treatments by galvaniem to the epinal and abdominal centers. But she returned to her home in a distant city during the summer, and while there suffered quite a relapse. December 10, 1897, intragastric faradism was begun and given, as a rule, three times a week till A pril 11, 1898. Massage was continued meanwhile daily, but by an unskilled attendant, and lavage was given two or three times a week. When the intragastric electricity was begun her stomach extended from the normal position above, to three and sometimes four inches below the level of the umbilicus. During the first three months of this treatment there was lese improvement than in any of my other The lower border of the stomach was still below the navel; but on persevering another month with all the meas ures and in addition administering full doses of a compound containing nuclo-albumins and bone marrow, she began to improve more rapidly. Now, the lower boundary of her stomach is one inch above level of the umbilicus, and she is stronger and better than for several years.

The percentage of free $\mathrm{HCl}$, formerly a little exoessive, has been lowered somewhat below the normal, but there has been no nausea or other noteworthy disturbance of digestion by the unusually long treatment of intragastric electricity.

There have been conflicting reports from other observers as to the effects of intragastric electricity, both on the muscles and glands of the organ. One denies that contractions of the stomach walls can be produced in this way. My cases, 4,5 and 6 above reported, are therefore of especial interest taken in connection with the preceding summary of the results in all of the fifteen cases in which I have em- ployed direct electrization of the stomach. They certainly establish beyond further question the fact that the motor function of the stomach can be powerfully stimulated by this means.

As to the effect upon secretion, the results above cited seem to indicate that this probably depends upon the dose and upon the degree of reaction. In the dose of faradism necessary to produce efficient muscular contractions there resulted in all except one of the cases with a normal or excessive percentage of free $\mathrm{HCl}$, a depression of the secretion. In cases of gastrectasia with chronic gastric catarrh and very deficient secretion, it agreed better than in most of the others, and in one of these, not reported here in full, the current from a cheap family faradic battery, with a coil of coarse short wire and not very rapid vibrator, applied through the intragastric electrode, seemed to help materially, along with massage, lavage, etc., in restoring the lost function of the glands, as well as in contracting the seriously dilated stomach. It is probable that the very slowly interrupted faradic current would effect contraction in this way with less risk of over-stimulating the glands, and I shall try this in my next suitable cases.

Too much emphasis can scarcely be placed upon the importance of these comparatively simple and safe methods of curing or ameliorating atonic dilatation of the stomacb. Large numbers of persons suffering from this serious condition are permitted to go without any efficient treatment, while others are submitted to the new surgical operation known as gastrorrhaphy or gastroplication, designed to reduce the size of the viscus. This may be necessary in extreme cases, but surely all other practicable means of relief should first be exhausted.

\section{REFERENCES.}

Diseases of the Stomach. By Prof. C. A. Ewald, M.D., New York, 1894 Loc. citat

Mathieu of the Diseases the Chronic Cator

the Boardman Reed, M.D. Jour. Am. Med. Assoc., Feb. 19, 1898.

mportant Indications and Contra-Indications for Massage of the Abdomen, with Report of Cases Show

A New Intragastric Slectrode for the Treatment of Gastralgia and Deficient Gastric Motility, With or Without Dilatation. Phila. Med. Jour., Meh, 26, 189 s.

\section{THE DIAGNOSIS AND TREATMENT OF DISEASES OF THE DUODENUM BY DIRECT METHODS.}

resented to the Section on Practice of Medicine at the Forty-ninth Annual Meeting of the American Medical Association, held at Denver, Colo., June, 7 10, 1898.

BY FENTON B. TURCK, M.D. CHICAOO.

The use of the gyromele in the diagnosis and treatment of intestinal diseases is now so well known by the profession that it would seem hardly necessary to describe the mothod, but as more work is being accomplished and new facts learned it is destined to add to our knowledge of the physiology and pathology of the gastro-intestinal tube. The gyromele as made for diagnosis, and treatment of the esophagus, stomach and intestines is modified for each part of the alimentary tube to which it is applicable, and also for the various kinds of uses in both diagnosis and treat. ment. The gyromele as is well known is composed of three essential parts. The cable with a spiral attached to one end and to the other end is attached an instrument for producing revolutions of the cable and spiral. To the end of the spiral is attached a 